\title{
Perfiles y especificidades del trabajo independiente cuentapropista en el escenario productivo actual. Un contrapunto entre los periodistas colaboradores de prensa y los diseñadores de indumentaria independientes*
}

\author{
María Laura Henry**
}

\section{Resumen}

En las últimas décadas, el trabajo se ha heterogeneizado y sus formas de ejercicio no se restringen ya al empleo asalariado típico. En este marco, el trabajo independiente cuentapropista despierta un renovado interés y surge como desafío analítico la necesidad de realizar precisiones al interior de esta categoría ocupacional, dado que su composición es sumamente diversa y conlleva condiciones de trabajo también dispares.

Este artículo busca contribuir a este campo de análisis, tomando como objeto a dos grupos de trabajadores: los periodistas colaboradores y los diseñadores de indumentaria independientes. Específicamente, el objetivo es determinar qué tipo de condiciones laborales se configuran para estas dos modalidades de empleo independiente cuentapropista, cuáles son los factores explicativos y qué ventajas y/o desventajas conllevan para los trabajadores en cada caso.

\footnotetext{
* Artículo recibido el 21 de Marzo de 2016. Aceptado el 25 de Junio de 2016.

** Facultad de Humanidades y Ciencias de la Educación-Universidad Nacional de La Plata. Correo electrónico: mlaurahenry@gmail.com
} 
En términos metodológicos, los resultados del artículo son fruto de una estrategia de investigación cualitativa que conjuga la revisión de fuentes documentales y la realización de entrevistas en profundidad a trabajadores.

\section{Palabras clave}

Cuentapropismo - Condiciones laborales - Trabajo independiente.

\section{Profiles and specificities of self-employed workers in the current production scenario. A counterpoint between freelance journalists and independent apparel designers \\ Abstract}

\section{Abstract}

In recent decades, work has diversified and its forms of exercise are no longer restricted to typical salaried employment. In this context, independent self-employment has aroused renewed interest and the analytical challenge that emerges is to make precisions within this occupational category, since its composition is extremely diverse and it also entails disparate working conditions.

This article seeks to contribute to this field of analysis, taking as object two groups of workers: freelance journalists and independent apparel designers. Specifically, the aim is to determine what kind of working conditions involve these two modalities of self-employment, what are the explanatory factors and what advantages and/or disadvantages are set for workers in each case.

In terms of methodology, the arguments of this paper are the result of a qualitative research strategy that combines the review of documentary sources and interviews to workers. 


\section{Keywords}

Entrepreneurism - Working conditions - Self employment.

\section{Introducción}

Algunas de las temáticas constantes en los estudios académicos sobre el trabajo de las últimas décadas han sido la crisis del empleo típico y la preocupación por las nuevas fisonomías que adopta el trabajo en el marco de modelos productivos cada vez más fragmentados, flexibles y desregulados. Dentro de estos debates, es frecuente la referencia al trabajo independiente cuentapropista, en tanto inserción ocupacional mediante la cual una parte de la población encuentra sus medios de subsistencia.

De allí, entonces, la relevancia de ahondar en el estudio de este grupo de trabajadores que constituye una categoría sumamente heterogénea, aún poco examinada y cuyos rasgos definitorios obedecen a distintos factores que deben ser debidamente analizados. Así, dentro de dicho conjunto, es posible encontrar trabajadores con diferenciales de calificación, de productividad, de ingresos $y$, fundamentalmente, con marcadas discrepancias en términos de la calidad de su condiciones laborales. Correlativamente, esto se refleja en la convivencia dentro de este segmento de cuentapropistas en situaciones altamente ventajosas -por ejemplo, algunas profesiones liberales- con otros que se hallan en situaciones más bien vulnerables y precarias -como los vendedores ambulantes-.

Se define así un campo de gran interés académico para los estudios del trabajo que consiste básicamente en analizar qué significa el trabajo independiente cuentapropista en el horizonte laboral actual y qué tipo de condiciones laborales ofrece a quienes lo desempeñan. Para ello, es primordial la realización de estudios empíricos que brinden información situada y referida a casos concretos sobre sus distintas manifestaciones, y que ayuden a establecer matices y perfiles distintivos en esta categoría ocupacional. Nuestro artículo, por lo tanto, pretende ser un aporte a este conjunto de reflexiones, tomando como objeto de estudio a los periodistas colaboradores -también llamados "freelance"- de la prensa escrita y a los diseñadores de indumentaria independientes. Específicamente, nos planteamos como objetivos determinar qué tipo de condiciones laborales se configuran para estas dos 
modalidades de empleo independiente cuentapropista, cuáles son los factores explicativos y qué ventajas y/o desventajas conllevan para los trabajadores en cada caso.

En cuanto a la estructuración del artículo, en primer lugar presentaremos la metodología sobre la cual se basan los argumentos del texto. En segundo término, haremos algunas reflexiones acerca del trabajo independiente y de su actual papel en la economía. A continuación, nos adentraremos de lleno en el análisis de los casos empíricos, comenzando por los periodistas colaboradores. Y, en este sentido, caracterizaremos la rama productiva donde se insertan, las recientes transformaciones de la misma y, posteriormente, las condiciones laborales que poseen estos trabajadores. Seguidamente, emprenderemos el análisis de los diseñadores de indumentaria independientes, también empezando con una descripción de su rama de pertenencia, para luego desarrollar las características que adquiere esta modalidad laboral. En el siguiente apartado realizaremos una comparación entre los dos grupos de trabajadores y un balance acerca de las similitudes y divergencias entre los mismos. Por último, ofreceremos algunas reflexiones a modo de conclusión.

\section{Metodología}

En términos metodológicos, los resultados del artículo son fruto de una estrategia de investigación de tipo cualitativo que conjuga, por un lado, una revisión de fuentes documentales orientada a contextualizar -en términos sectoriales y productivos- las actividades laborales bajo estudio y, por otro, la realización de entrevistas en profundidad a periodistas colaboradores y a diseñadores de indumentaria independientes.

En cuanto a la revisión documental, y a los fines de contextualizar sectorialmente las dos formas de trabajo bajo estudio, ha sido fundamental la revisión de datos secundarios provistos tanto por estudios académicos como por reportes y documentos generados por diversas instituciones del sector -observatorios, sindicatos, asociaciones, ONG, etc.-. En este

punto, cabe señalar que la -relativamente- abundante cantidad de información disponible sobre la producción de diseño de indumentaria en Argentina contrasta con la escasez de datos referidos a la composición y al desempeño económico de la rama de prensa escrita, lo cual hizo esta indagación más laboriosa.

En cuanto a las entrevistas en profundidad a trabajadores, también cabe señalar que la mayor extensión del trabajo de campo para el caso de los periodistas colaboradores se debió 
a la casi nula existencia de antecedentes de investigación en nuestro país. En cambio, para los diseñadores de indumentaria, pudimos contar con importantes antecedentes locales de investigación académica, incluyendo dos tesis de posgrado sobre la temática (Correa, 2010; Miguel, 2010). Estos antecedentes tan minuciosos, juntos con otros (Guerschman, 2010; Marino 2012; Mon, 2012), nos permitieron llevar adelante un trabajo de campo más acotado para este otro grupo de trabajadores, sin que ello implicara perder validez sobre los resultados encontrados. Antes bien, el cotejo y triangulación de hallazgos nos permitieron encontrar muchas similitudes y puntos de contacto con dichos estudios anteriores.

En términos específicos, se realizaron catorce entrevistas a periodistas que se desempeñaban bajo la modalidad de colaboradores. Para seleccionarlos, se estableció una serie de criterios: que tuviesen distintas especializaciones temáticas, que trabajasen para un amplio abanico de publicaciones en el ámbito de la ciudad de Buenos Aires y que llevaran al menos seis meses dedicándose a la modalidad bajo estudio. Por otro lado, se realizaron cinco entrevistas en profundidad a diseñadores de indumentaria independientes, que respondieron también a los criterios de haberse desempeñado en su actividad por al menos seis meses, poseer distintas especializaciones -producción de ropa, de calzado, de accesorios, entre otros- y tener su epicentro operativo en la zona metropolitana.

Para poder acceder a estos dos grupos de trabajadores, fueron de gran ayuda los contactos iniciales con diversos informantes clave, conocedores del campo. Ellos sirvieron como punto de partida para la búsqueda de entrevistados a través del procedimiento de referenciación o "técnica de bola de nieve". Esta vía resultó ser la más adecuada para localizar trabajadores que se hallan por fuera de los límites de una organización, que no figuran en ninguna base de datos general de la actividad, pero que comparten densas redes sociales e instancias de intercambio entre ellos. En estos contextos, la "técnica de bola de nieve" es efectiva como forma de identificar potenciales entrevistados (Verd Pericás y Martí Olivé, 1999) y permite arribar a una muestra de tipo intencional, por medio de la cual escenarios particulares y personas son seleccionados en términos de relevancia y adecuación para el problema abordado (Maxwell, 1996).

En cuanto a las características tempo-espaciales del trabajo de campo, el mismo fue realizado en el periodo 2012-2013 en el ámbito de la ciudad de Buenos Aires y alrededores. Este recorte espacial cobra todo su sentido dada la concentración que allí tienen ambas 
actividades. Los estudios corroboran esta mayor presencia de los diseñadores de indumentaria independientes en el área metropolitana de Buenos Aires (Marino, 2012) y, para el caso de la rama de prensa en Argentina, es conocido el fenómeno de "los grandes diarios" y revistas de amplia circulación en todo el territorio, pero cuyo foco productor está situado en la ciudad de Buenos Aires.

\section{El empleo independiente y sus significados en el horizonte laboral actual}

\subsection{La conformación del trabajo independiente}

Para comprender cabalmente la conformación de la categoría de trabajador independiente, necesariamente debemos comenzar haciendo una genealogía de su contraparte, es decir, del trabajo subordinado. La razón es que se definen mutuamente por oposición, siendo el segundo el que actúa como "demarcador" para ambos.

Como es sabido, las condiciones estructurales en las cuales funciona la producción en nuestras sociedades capitalistas, donde solo una fracción es propietaria de los medios de producción, hace que la gran mayoría de las personas deba vender su fuerza de trabajo como medio para subsistir. Este condicionamiento es lo que subyace a la progresiva difusión de unas relaciones de producción que son específicas de nuestras sociedades modernas: las relaciones de trabajo, que tienen lugar entre dos actores, que podemos definir ampliamente como empleador y trabajador.

Esta relación de trabajo históricamente constituida tiene una serie de rasgos también conocidos, entre los que sobresale la denominada subordinación. Para que puedan entrar en vinculación empleador y trabajador hubo que encontrar la forma de hacer del trabajo un objeto posible de contrato. Supiot (2000) explica que en tanto el capitalista no puede tomar posesión de la cosa alquilada -el trabajador-, lo que compra es un determinado tiempo donde el individuo deberá hacer lo que se le ordena en el marco de un proceso de producción. De ahí que la subordinación haya devenido la forma en la que el capitalista entra en posesión del bien fuerza de trabajo y que el control jerárquico sea un aspecto inherente a esta vinculación.

Esto último nos lleva a otro punto inherente a toda relación laboral: la asimetría entre los actores que participan de la misma. Si los trabajadores están estructuralmente obligados a 
vender su fuerza de trabajo para subsistir y luego, una vez en los establecimientos, se hallan bajo el control sistemático de su empleador, es difícil sostener la idea de que se trata de individuos que participan de dicha relación en pie de igualdad. El reconocimiento de este desequilibrio de fuerzas y la preocupación por atenuarlo -o al menos regularlo- fue el origen de un corpus normativo específico: el derecho laboral.

Nótese entonces que la existencia de subordinación jurídica es el criterio que permite establecer la existencia de trabajo en relación de dependencia y su regulación por medio de una serie de normas específicas del derecho laboral. De igual forma, este mismo criterio nos permite comprender en qué consiste el trabajo independiente y sus alcances en términos de su oposición con el primero. Así, el trabajo independiente quedó definido como una forma de ejercicio del trabajo donde los individuos establecen autónomamente las condiciones y formas organizativas del proceso de producción, y usan sus propias maquinarias, instalaciones o instrumental.

Luego, dentro de los independientes, existe una clasificación ulterior que diferencia a quienes tienen otros trabajadores a su cargo -empleadores- y quienes ejercen sus labores de forma individual, sin otras personas involucradas: los cuentapropistas. Este último es el grupo que aquí nos ocupa y que será objeto de nuestras reflexiones. En su versión más clásica, el cuentapropismo quedó asociado a las tradicionales figuras del artesano, del agricultor o del profesional liberal; o sea, trabajadores en los cuales sobresale con nitidez la autonomía y la libertad en la organización de sus labores en tanto rasgo definitorio.

En cuanto a la regulación que rige el trabajo independiente, el mismo se encuentra totalmente al margen del régimen jurídico del derecho del trabajo y, por lo tanto, las obras o servicios que realizan se encuentran abarcados por el denominado derecho común o civil. Podría decirse, pues, que los autónomos no gozan de otra protección que la que emerge de las cláusulas contractuales que ellos mismos logran concertar.

Llegados a este punto, es importante notar que -al menos analíticamente- el trabajo independiente ha sido construido de forma subordinada y como grupo residual respecto del trabajo en relación de dependencia y, en este sentido, han sido escasos los intentos por determinar sus elementos constitutivos y sus modalidades de existencia (Bologna, 2006).

Para el caso de nuestro país, por ejemplo, podemos encontrar algunos estudios valiosos sobre la temática (Gallart et al., 1990; Donaire, 2007; Lepore y Schelser; 2006; Bertranou y 
Maurizio, 2011; Jiménez, 2011). Los mismos abordan en cierta medida la composición del trabajo independiente, pero con un enfoque cuantitativo de nivel de análisis meso y macro.

Ciertamente, estos estudios antecedentes proveen un buen punto de partida, pero un análisis más complejo del trabajo independiente puede verse enriquecido si son complementados por otros esfuerzos interpretativos más cercanos al terreno y orientados a casos empíricos concretos. Estos pueden ofrecer argumentaciones interesantes a la hora de explicitar los elementos contextuales que afectan el comportamiento del trabajo independiente en sus diversas modalidades.

\subsection{Los actuales debates en torno al trabajo independiente cuentapropista}

Durante gran parte del siglo $\mathrm{XX}$, el trabajo subordinado y el trabajo independiente cuentapropista fueron perfilándose, primero, como dos condiciones mutuamente excluyentes a partir de sus marcadas diferencias y donde discernir la naturaleza de cada caso era algo "simple, evidente y casi intuitivo" (Goldin, 2011: 312). Segundo, como dos situaciones que a su interior se consideraban bastante homogéneas. Esto último se debió a que el trabajo subordinado adquirió unos rasgos sumamente estructurados durante la época de posguerra, lo cual dio lugar a la conformación de una norma de empleo típico ${ }^{1}$, mientras que, por su parte, el empleo independiente cuentapropista se suponía abarcaba primordialmente las figuras tradicionales ya mencionadas: artesanos, agricultores, comerciantes, profesionales liberales, entre otros.

Actualmente, y a diferencia de aquel contexto histórico, las cosas no son tan sencillas ya que las definiciones ocupacionales establecidas se hallan interpeladas por las transformaciones en curso. Así, surgen importantes interrogantes en torno a los contenidos que hoy adopta el trabajo independiente cuentapropista, debido a que el mismo parece haberse complejizado por el hecho de abarcar situaciones laborales cada vez más disimiles. Bajo los esquemas productivos actuales esta forma de trabajo no responde solo a la paradigmática figura del cuentapropista clásico ya que, por ejemplo, sus prestaciones se

\footnotetext{
${ }^{1}$ Esta forma típica ideal de empleo asalariado se caracterizó por los siguientes rasgos: trabajo subordinado de manera formal al capital a partir de un contrato en relación de dependencia; de tiempo completo, según jornada máxima legal vigente; desarrollado en el ámbito de un establecimiento productivo; con estabilidad y certidumbre en cuanto a su duración; registrado ante las instituciones de seguridad social; con salario y condiciones de trabajo regulados por convenio colectivo (Neffa, 2010).
} 
hallan estrechamente imbricadas con procesos productivos más amplios y también porque consisten en actividades cada vez más variadas (Bologna, 2006; Bögenhold, 2003; Stanworth y Stanworth, 1995; D'Amours y Crespo, 2004).

El desafío analítico actual reside entonces en revisitar al trabajo independiente cuentapropista en tanto objeto de estudio, superando algunas de las premisas sobre las cuales fue construido originariamente como categoría ocupacional. Puntualmente, debemos ahondar dentro de la misma y realizar una serie de precisiones a su interior. Se trata de una categoría sumamente heterogénea y cuya conformación obedece a distintos factores que, en general, no son debidamente estudiados. Esta falta de diferenciación interna lleva a una visión reduccionista e incluso a la conformación de retóricas unívocas -de signo positivo o negativo- sobre la naturaleza del trabajo independiente.

Al respecto, Smeaton (2003) y Tremblay y Genin (2010) indican la existencia dos grandes interpretaciones en disputa sobre la condición actual del trabajador independiente cuentapropista. Por un lado, encontramos aquellas voces que lo igualan a la precariedad y la informalidad, viendo en el mismo una condición padecida y de refugio para aquellos que no han logrado insertarse en el mercado de trabajo como asalariados. Inversamente, otros analistas ensalzan las virtudes de la independencia y lo consideran la modalidad elegida por quienes desean libertad respecto de las restricciones organizacionales y por quienes poseen una vocación emprendedorista, con la promesa de un crecimiento en el largo plazo hacia proyectos de mayor envergadura.

Para escapar de estas visiones reduccionistas es conveniente acercarse a situaciones concretas y a contextos específicos. Nuestro artículo se suma a esta propuesta analítica a partir de un estudio empíricamente fundamentado, tomando como objeto a dos grupos de trabajadores: los periodistas colaboradores y los diseñadores de indumentaria independientes. A continuación, veremos en qué consisten sus actividades y en qué sentido pueden ser objeto de un contrapunto analítico que abone este campo de reflexión.

\subsection{El trabajo de los periodistas colaboradores y de los diseñadores de indumentaria: particularidades y puntos de contacto}

Para comenzar, resulta pertinente hacer una breve descripción sobre el tipo de tareas que realizan los trabajadores bajo análisis. Los colaboradores son periodistas que se caracterizan 
por el hecho de que venden unidades de trabajo -artículos, notas- a uno o varios compradores, en este caso diarios o revistas. Existen básicamente dos estrategias por medio de las cuales logran vender su trabajo. Una forma consiste en presentar "sumarios" resúmenes acerca del contenido de las futuras notas- en distintos medios que si eventualmente le interesan al editor las comprará. Otra posibilidad es que el editor le encargue las notas al colaborador, lo cual generalmente sucede cuando ya existe cierta vinculación duradera de intercambios. En ambos casos, el editor de cada sección o suplemento es la persona que, a nombre de la empresa, se encarga de asignar qué contenidos serán realizados por el personal de planta de la redacción y cuáles serán provistos por colaboradores.

En cuanto a los diseñadores de indumentaria independientes ${ }^{2}$, se trata de trabajadores a cargo de pequeños emprendimientos orientados a la producción de prendas, accesorios, calzados y otros ítems de vestimenta, que tienen como elemento distintivo su creatividad, su innovación y su originalidad -en las formas, los materiales usados, en su propuesta estéticarespecto de los productos masivos de mercado. En este sentido, estos trabajadores se orientan a elaborar cantidades acotadas de mercancías -lo cual preserva su relativo grado de exclusividad- y tienen a su cargo todas las fases del proceso productivo: desde la concepción y el diseño propiamente dicho hasta la venta y comercialización de sus productos.

Cabe señalar que ambos grupos de trabajadores comparten ciertas características comunes que los vuelven pasibles de una comparación relevante. Primero, éstos pertenecen a un segmento específico dentro de los independientes en términos de sus calificaciones. En este sentido, los dos están altamente formados y profesionalizados. En el caso de los periodistas, se trata de trabajadores intelectuales que generan los contenidos escritos -artículos, crónicas, investigaciones, etc.- siempre cambiantes y originales que aparecen en las publicaciones de prensa. Si bien no es un requisito para ejercer, una gran parte de estos trabajadores se ha formado en instituciones universitarias y terciarias, lo cual denota su alto grado de preparación. Por su parte, los diseñadores de indumentaria también son trabajadores que en los últimos años han conocido un proceso de profesionalización acentuado. En el mismo, fue

\footnotetext{
${ }^{2}$ Cabe señalar que esta es la denominación que los trabajadores se dan a sí mismos en esta actividad y aunque no agreguemos el término "cuentapropista" por esta razón, en todos los casos nos estaremos refiriendo a este grupo específico, es decir, que no tienen personal a su cargo).
} 
clave la proliferación de carreras terciarias y universitarias orientadas a la enseñanza del diseño en tanto disciplina con identidad propia (Guerschman, 2010) ${ }^{3}$.

Segundo, estos trabajadores pueden ser comparados en términos del sector al cual pertenece su actividad: las industrias creativas. Este término designa a aquel sector de la economía que tiene como rasgo esencial la producción de bienes y servicios que poseen un carácter fuertemente simbólico, creativo y estético. De esta manera, las industrias culturales son un sector muy amplio -abarcan actividades tan dispares como los medios de comunicación, la música, el diseño, el cine, etc.- que tienen en común el hecho de conjugar una dimensión cultural en sus producciones -transmisión de mensajes, valores, ideas- con una dimensión económica, ya que también están destinadas a valorizarse en el mercado y a generar ganancias (Zallo, 1988; UNCTAD, 2010).

De esta forma, los periodistas colaboradores y los diseñadores de indumentaria independientes pertenecen a una franja -bastante puntual- dentro del trabajo independiente: son altamente calificados y se desempeñan en un sector de actividad muy dinámico en las económicas actuales. A priori, podría intuirse que por su perfil específico tienen condiciones laborales similares y predominantemente ventajosas. Sin embargo, cabe preguntarse si esto es realmente así o si, por el contrario, existen una serie de especificidades que quedan opacadas al mantenernos en este nivel de análisis, todavía general e indeterminado.

Para brindar una posible respuesta a este interrogante, en lo que sigue del artículo desarrollaremos un estudio pormenorizado de ambos casos, primero examinando la trama sectorial en la que se insertan y segundo, analizando sus condiciones laborales en función de los siguientes tres ejes: i) el grado de autonomía operativa que tienen en el desarrollo de su actividad; ii) el mercado en el que se desempeñan y el tipo de demanda a la que responden; iii) los pagos e ingresos que reciben, así como sus posibilidades de acumulación.

De los hallazgos en cada uno de estos ejes podrá ulteriormente llegarse a un contrapunto más específico que permita elaborar un balance en términos de su significado dentro del universo del trabajo independiente cuentapropista.

\footnotetext{
3 Los datos de una encuesta nacional realizada en 2012 a diseñadores independientes (Marino, 2012) permitieron establecer que la mayoría de ellos se ha formado en instituciones educativas universitarias (54\%) y terciarias (32\%). Otros recibieron una formación de tipo técnica (10\%) y solo un bajo porcentaje dijo no haber recibido ninguna formación (4\%).
} 


\section{El trabajo de los periodistas colaboradores}

\subsection{Evolución de la rama de la prensa escrita argentina y tendencias en torno al empleo}

Las empresas de prensa han implementado en los últimos años un conjunto de estrategias para mantenerse competitivas en el mercado y lograr una estructura de costos satisfactoria (Henry, 2010 y 2013; Mastrini y Becerra, 2006; Postolski et al., 2007). Al respecto, una de las cuestiones que las empresas buscan adaptar a sus necesidades es su dotación de fuerza de trabajo y la utilización que hacen de la misma. En este escenario, la organización del trabajo de los periodistas de prensa y todo su circuito de producción se ha modificado extraordinariamente en los últimos tiempos a partir de dos fenómenos complementarios propiciados por las empresas.

Primero, se ha producido un proceso de intensificación del trabajo de los periodistas estables, fundamentalmente a partir de la introducción de nuevas tecnologías. Así, en esta rama la tecnología ha permitido un proceso productivo casi continuo, así como una adición de tareas inéditas para los redactores que se ven empujados a procesar y generar mayores volúmenes de información en menor tiempo.

El segundo fenómeno -complementario del primero- hace referencia a una flexibilidad de tipo externa o numérica que las empresas de prensa favorecen a partir de la creciente utilización de figuras atípicas y temporales que les permite una provisión de mano de obra a bajo costo y que pueden aumentar o reducir a discreción con mínimos impedimentos. Tal es el caso de los periodistas colaboradores, que son remunerados por artículo y que han ido ganando un peso progresivo dentro de los procesos productivos de la prensa escrita como componentes esenciales de los mismos.

En nuestro país no existe todavía ningún registro exhaustivo sobre la dimensión del empleo -formal o informal- de la prensa escrita y este vacío estadístico es casi total en el caso de los periodistas colaboradores, donde las condiciones en las cuales desarrollan sus tareas ausencia de registro, intermitencia, eventualidad-impiden efectuar mediciones concretas. De todas formas, el sindicato de la actividad (UTPBA, Unión de Trabajadores de Prensa de Buenos Aires) y nuestros informantes clave han ratificado la realidad de esta tendencia 
referida al crecimiento de la proporción de colaboradores por sobre los periodistas estables, sobre la base de indicadores indirectos tales como la reducción del empleo en blanco en el sector y el achicamiento progresivo de las redacciones.

Llegados a este punto, es importante señalar que el periodismo tiene una larga tradición de trabajo freelance -tal como ocurre en otras industrias culturales-, y la existencia de esta figura laboral no es un fenómeno nuevo. En este sentido, el Estatuto del Periodista Profesional $(E P P)^{4}$ contempla la existencia de los colaboradores, pero con carácter de excepción: personas requeridas transitoria o accidentalmente para generar la información sobre acontecimientos determinados y que serán remuneradas por cada crónica o comentario (artículo 65). Aquí debemos señalar dos cuestiones importantes: primero, la labor de estos trabajadores debe corresponder a tareas no habituales y segundo, vinculado con lo anterior, el EPP pone como límite para las empresas que estos periodistas solo puedan escribir hasta veinticuatro colaboraciones anuales. Una vez que superan ese número de notas, el trabajador adquiere la calidad de "colaborador permanente", que implica una relación de dependencia con su empleador, permitiéndole acceder a todos los beneficios del contrato de trabajo y del $\mathrm{EPP}^{5}$.

De esta manera, el EPP buscó contemplar la necesidad fortuita por parte de las empresas de contar con periodistas contratados para cubrir hechos puntuales o con informadores conocedores de temas específicos en una coyuntura dada. Pero cuando esta supuesta eventualidad se convierte en una práctica recurrente, debemos vincular esta práctica de las empresas con una dinámica de reducción de costos: el sistema de remuneración por unidad de trabajo les permite adaptarse a las fluctuaciones de la actividad y reducir los costos fijos que implica una plantilla de trabajadores estables. En este sentido, esta estrategia puede

\footnotetext{
${ }^{4}$ La ley 12.908, conocida como el Estatuto del Periodista Profesional, regula las condiciones laborales para el trabajo en empresas periodísticas. Así, en sus sucesivos artículos, el EPP reglamenta distintos aspectos tales como las condiciones de estabilidad, jornada, vacaciones, accidentes, enfermedades y salarios, entre otras. Cabe señalar que este estatuto reviste un carácter más protectorio que lo establecido en la legislación laboral vigente para la generalidad de los trabajadores. Esto se debe a los fuertes componentes constitucionales en la profesión y la alta exposición e influencia social de la misma (Arese, 2004).

${ }^{5}$ Un aspecto importante a señalar es que si bien el periodista sigue cobrando por pieza de trabajo, bajo esta nueva categorización puede acceder, entre otros beneficios, a una indemnización en caso de no ser requerido por su empleador. Esto le provee cierto grado de certidumbre acerca de su continuidad laboral.
} 
inscribirse en la lógica de la sub contratación o externalización, ya que apunta a que los equipos de redacción permanentes sean cada vez más restringidos (Aubert, 2007).

Es interesante notar entonces el papel paradójico que juega el EPP en la viabilidad de esta situación ya que el -creciente- uso de periodistas colaboradores es posible debido a que, por su tradicional presencia en el sector, se hallan contemplados como categoría profesional en el EPP. En un contexto de mayor propensión a la externalización y al uso de vínculos contractuales no laborales, estas categorías legales de larga data proveen una solución relativamente aceptable para las empresas, que no necesitan introducir formas de empleo totalmente nuevas y que pueden ser percibidas como altamente disruptivas respecto a los arreglos vigentes.

Por eso, bajo este tipo de contextos -que favorecen la flexibilidad- es clave realizar un examen atento a las condiciones reales bajo las cuales se desempeñan los trabajadores para evaluar qué tipo de empleo se configura, más allá de sus aspectos legales-formales. Se trata de un ejercicio sumamente necesario en tanto, como señala Poblete (2008), siempre existe una distancia insalvable entre lo que dicta la norma laboral y su puesta en práctica. Aquella no puede jamás contemplar todas las variaciones de casos posibles que pueden existir en la realidad, así como tampoco puede evitar la existencia de puntos ambiguos que abran la puerta a prácticas "poco ortodoxas", pero que sin embargo no llegan a violar la norma. Veamos entonces de qué forma desarrollan su trabajo los periodistas colaboradores.

\section{2- Las condiciones de trabajo de los periodistas colaboradores: una independencia con restricciones}

A través de las entrevistas de nuestro trabajo de campo hemos podido acceder en detalle a la dinámica de trabajo real que llevan adelante los periodistas colaboradores y conocer mejor la organización de sus tareas y los lineamientos que toman en cuenta al hacerlas. Al respecto, uno de los aspectos que primero resaltaron nuestros entrevistados, en términos positivos, fue el amplio margen de autonomía con el que cuentan para desarrollar su trabajo. Ante la pregunta acerca de cómo definen el contenido de las notas y sobre sus intercambios con los editores, la mayoría de los colaboradores señaló recibir solo instrucciones generales y poco precisas: la extensión en caracteres, la fecha de entrega, algún breve comentario sobre el enfoque de la nota y poco más. 
Del editor, en general, no recibís muchas instrucciones. Te dice que tenés que cubrir un recital tal día... y si es un festival, que trates de darle bola a las tres bandas principales y después hacés lo que querés. Las consignas son muy puntuales. Si te doy un mail con las instrucciones que me da un editor, capaz que ni sabés qué me quiso decir. O nada, no me dicen nada. Te dan toda la libertad. (Ignacio, colaborador) ${ }^{6}$.

Lejos de ser un problema, muchos de nuestros entrevistados ven esta situación como positiva y exaltan el valor de la independencia que les provee su modalidad de trabajo. Después de todo, la autonomía siempre ha constituido uno de los elementos con los cuales los trabajadores profesionales distinguen su estatus respecto de otras ocupaciones menos calificadas y de naturaleza más prescripta. Asimismo, en el discurso de los periodistas colaboradores también emerge como ventaja la flexibilidad -entendida aquí como libertadque tienen para manejar sus tiempos y el lugar de trabajo, que puede ser su hogar o cualquier otro sitio.

Sin embargo, aunque estos trabajadores señalen contar con gran autonomía operativa, ésta dista de ser completa. Existe toda una serie de condicionantes que surgen por el hecho de participar en la elaboración de un producto complejo -el diario o revista-, que es de producción colectiva a partir de una estricta división de roles y cuyos contenidos deben ajustarse a ciertos lineamientos -políticos, simbólicos, culturales- que son determinados cupularmente por la empresa a través de la llamada línea editorial. De esta manera, más que la existencia de directivas explícitas o de alguna clase de control-supervisión, es el tipo de proceso productivo del cual participan lo que les impone a los periodistas colaboradores ciertos parámetros en base a los cuales ajustar su labor.

Tenés que captarle la onda. Totalmente. No solo al editor, sino al medio, a las condiciones del medio. (Ana, colaboradora).

\footnotetext{
${ }^{6}$ Los nombres de todos los trabajadores que nos brindaron sus relatos fueron cambiados por seudónimos para preservar la confidencialidad de los mismos.
} 
La palabra "cierre" para un periodista es como la palabra sagrada. Es una especie de religión y no podés traicionar eso. Si alguien te pidió una nota para tal día, no dormís pero llegás al cierre. (Ignacio, colaborador).

Luego, la posibilidad que tienen los colaboradores de vender sus notas en distintos diarios y revistas puede llevar a conjeturar que se trata de profesionales freelance, en condiciones de hacer valer sus calificaciones en el mercado y de practicar el "emprendedorismo". Se podría presumir asimismo que trabajar para varias publicaciones significaría la posibilidad de gestionar sus trayectorias y de mejorar sus ingresos a partir de la diversificación laboral. De hecho, muchos de nuestros entrevistados señalan esta potencialidad.

No obstante, cuando nos acercamos a las realidades cotidianas de los periodistas colaboradores, encontramos que el "emprendedorismo" tiene una cara menos ventajosa. En primer término, no es tan sencillo para estos trabajadores disponer de un cúmulo de compradores potenciales que le permita lograr un nivel de actividad alto y sostenido en el tiempo. El número de revistas y diarios existentes en Buenos Aires representa ciertamente un número acotado y no llega a configurar una demanda múltiple e ilimitada. Este rasgo se acentúa por el hecho de que los colaboradores se especializan en ciertos temas espectáculos, deportes, tecnología, etc.-, lo cual los sitúa en un nicho aun más específico de trabajo. En este sentido, estos trabajadores deben desarrollar un esfuerzo permanente por mantener su nivel de actividad:

A la noche sigo pensando... Pensando qué hacer para generar otras cosas, más trabajo. Porque todo es temporario... (Carolina, colaboradora).

Al no tener un contrato con vos... ese es el riesgo y esas son las condiciones de laburo que te pesan (...) Cuando empecé, cada vez que entregaba una nota, sentía que me estaba jugando que me volvieran a llamar, ¿entendés? (Lucía, colaboradora).

En tanto su mercado no se halla formado por una multiplicidad de clientes, es lógico que estos periodistas busquen asegurarse un flujo regular de trabajo intentado establecer 
intercambios repetidos en el tiempo con las publicaciones existentes, aun a costa de tener que eludir la normativa que establece el EPP respecto de las 24 colaboraciones anuales.

Otro punto a resaltar es que los términos en que los periodistas colaboradores reciben su paga son sumamente flexibles y arbitrarios. Solo aquellos periodistas con calificaciones técnicas poco tradicionales o que gozan de cierto renombre pueden llegar a negociar altos honorarios. Se trata de un aspecto completamente desregulado en la actividad ya que, en teoría, por tratarse de un intercambio mercantil y ocasional, debe quedar sujeto al libre convenio de las partes. Lo que ocurre de hecho es que estos trabajadores son tomadores de precio en un contexto de pagos desregulados y que varían de una empresa a otra.

- Y las tarifas vienen dadas, ¿no? ¿Vos te podés sentar a negociar eso?

- Bajo ningún punto de vista. No tenés chance. En cuanto levantás la voz sobre eso, podés tener problemas. Porque el mercado está tan pauperizado que si no estás vos, viene otro. Siempre va a haber un colaborador que por esta plata haga la nota. (Ana, colaboradora).

Además, los periodistas colaboradores solo cobran si la nota ha sido publicada, cosa que puede demorarse en el tiempo e incluso no suceder debido a que los editores pueden posponer su publicación sobre la base de distintas razones. Por último, en caso de que la nota efectivamente sea publicada, el cobro recién se efectiviza semanas e incluso meses después.

Puede ser, por ejemplo, que te "parrilleen" una nota. Que suele suceder, que te la tengan seis meses. Porque aparte también le servís al medio para asegurarse cierta producción permanente. Entonces si no lo necesitan, no lo publican. ¡Pero vos no lo cobrás! (Natalia, colaboradora).

En suma, es evidente que si bien los periodistas colaboradores están insertos en marcos que los alientan a comportarse como si fueran "emprendedores", en la mayor parte de los casos se trata de una condición ficticia e inviable. Reciben ingresos escasos, disociados de cualquier regulación y sujetos a las arbitrariedades de cada editor o empresa. Asimismo, la 
inestabilidad propia de su trabajo no les permite generar un horizonte de previsibilidad $y$, menos aun, algún margen de acumulación que permita pensar que estos trabajadores llegan a esta modalidad laboral atraídos por las ventajas económicas de la misma.

A continuación veremos cómo se presentan las condiciones laborales para los diseñadores de indumentaria para, posteriormente, establecer una comparación entre ambos casos.

\section{Los diseñadores de indumentaria independientes}

\subsection{La consolidación del diseño de indumentaria independiente en Argentina y los} rasgos distintivos de su producción

Deben tenerse en cuenta algunos procesos económicos y ciertos cambios en las pautas de consumo en las últimas dos décadas en nuestro país para comprender cabalmente el desarrollo del diseño de indumentaria independiente como un campo con perfil propio al interior del sector.

Al respecto, Miguel (2010) destaca que su desarrollo se catalizó en un contexto adverso para la industria de indumentaria local, siendo una derivación paradójica de esta situación de crisis general de la actividad. Como es ampliamente sabido, durante la década del noventa el sector textil sufrió una fuerte contracción debido a la instauración de un modelo económico aperturista, que favoreció la entrada indiscriminada de productos importados a bajísimo costo y que tuvo importantes consecuencias tanto en el desempeño de las empresas como en términos de empleo ${ }^{7}$.

Según autores como Miguel (2010) y Guerschman y Vargas (2007), este contexto económico adverso tuvo, sin embargo, una rol impulsor para el desarrollo del campo específico del diseño independiente de indumentaria. Por un lado, porque la crisis de la industria repercutió negativamente en el mercado laboral y generó la conformación de una masa de diseñadores que no encontraba empleo en relación de dependencia y que se vio impulsada a desarrollar sus propios emprendimientos. Por otro lado, los crecientes procesos

\footnotetext{
${ }^{7}$ Kosakoff (2004) señala que el Complejo Textil Argentino, donde se haya incluido el sector de indumentaria, atravesó durante la década de los noventa y los comienzos del nuevo milenio por su mayor crisis en más de cincuenta años: entre 1993 y 2001, el valor agregado del sector Indumentaria se contrajo un 37\%, la demanda interna cayó un $36 \%$ y el número de trabajadores ocupados se redujo un $51 \%$.
} 
de tercerización en el sector y la consecuente multiplicación de pequeños talleres de confección permitieron que fuese accesible para los diseñadores independientes la producción de acotados volúmenes de mercadería y pequeñas colecciones. De esta forma, explica Miguel, pudieron tomar control de la cadena productiva en su totalidad haciendo uso de la estructura desverticalizada del sector ${ }^{8}$.

Como señala Mon (2012), esta modalidad de producción de indumentaria se caracteriza por la concentración de roles en el diseñador independiente, que interviene en todos los puntos del proceso de elaboración de una prenda u accesorio: comenzando por la concepción y diseño, interviniendo en el proceso de confección y llegando hasta la difusión y comercialización de sus productos.

Por otra parte, ha sido fundamental para la consolidación de la actividad la existencia de un creciente público consumidor de indumentaria de diseño -de perfil joven-adulto y de nivel socioeconómico medio- que se ha mostrado receptivo a estas propuestas estéticas alternativas y que busca originalidad e innovación cuando adquiere estos bienes (Vargas, 2007; Correa, 2009).

Por último, podemos destacar el rol que han jugado instituciones estatales y públicas al promover estos emprendimientos autogestionados, confiando en las potencialidades del llamado "factor diseño" para generar actividades económicas sustentables y con capacidad para fomentar la innovación de productos. En este sentido, el Centro Metropolitano de Diseño (CMD) de la ciudad de Buenos Aires, el Programa de Diseño del Instituto Nacional de Tecnología Industrial (INTI) y la fundación ProTejer, que reúne a todos los sectores de la cadena de valor de la Agro Industria Textil y de Indumentaria de la Argentina, son algunas de las instituciones que brindan a los diseñadores independientes apoyo en la difusión de sus actividades, capacitación, financiamiento y ayuda para el establecimiento de nuevos canales de comercialización (Pérez Zelaschi, 2012; Marino, 2011).

Con la confluencia de estos factores, paulatinamente se ha desarrollado un próspero mercado para indumentaria de diseño y la multiplicación de los canales de distribución y

\footnotetext{
${ }^{8}$ La posibilidad de terciarización no llega a convertir el proceso productivo en un procedimiento netamente industrial. Esto se debe a que los diseñadores independientes se encargan de realizar las terminaciones del producto una vez que lo han recibido de los talleres, donde solamente se hacen las costuras y ensambles más "gruesos". Esta combinación de técnicas mecánicas con otras artesanales es justamente lo que permite la elaboración de productos distintivos en sus formas, estética y calidad.
} 
comercialización: ferias, exposiciones, pequeñas tiendas especializadas, que incluso llegan a conformar circuitos de gran interés para los interesados en consumir estos productos. En este sentido, en la ciudad de Buenos Aires - principal epicentro del diseño en nuestro país9 existen espacios geográficos claramente asociados a esta actividad tales como el barrio de San Telmo y, fundamentalmente, la zona de Palermo (Guerschman, 2010).

\subsection{Las condiciones de trabajo de los diseñadores de indumentaria independientes}

A través de nuestras indagaciones sobre la actividad de los diseñadores de indumentaria independientes pudimos encontrar que se trata de una modalidad laboral donde el margen de discreción que tienen estos trabajadores para realizar sus tareas es muy alto. Sobre la base de decisiones propias definen qué tipo de productos desean realizar, qué características tendrán los mismos -en términos de cantidad y calidad- y cómo serán elaborados.

En la etapa de concepción, donde el diseñador basa sus opciones en diversas cuestiones tales como "algo que lo inspiró" -fotos, lugares, situaciones, etc.-, un concepto estético que le gustaría aplicar a sus mercancías, algo que le gustaría ponerse, la temporada en la cual va a vender, entre otras.

Siempre uno suele tener en la cabeza qué es lo que tiene ganas de hacer o para qué lado quiere ir. Entonces si necesitás inspiración, empezás a buscar imágenes sobre eso, diseñadores de afuera que laburen de la misma forma, texturas... Y así empezás a hacerte como una imagen o una carta de imágenes de donde vos podés extraer colores, paletas para usar. (Paola, diseñadora).

Este grado de autonomía es lógico, teniendo en cuenta que allí se genera el mayor valor agregado de su producción y su principal ventaja competitiva: la capacidad de generar mercancías altamente diferenciadas con importantes cuotas de creatividad.

En cuanto a su mercado, estos trabajadores se insertan en el mismo de una manera "clásica", es decir, con determinadas mercancías que ofrecen para la venta y con variables

\footnotetext{
${ }^{9}$ La mayor visibilidad y consolidación local del diseño (en todas sus vertientes) ha llevado, por ejemplo, a que la UNESCO nombre a Buenos Aires como la primera Ciudad Creativa del Diseño en 2005.
} 
chances de que efectivamente vayan a ser adquiridas por el público. Así, los clientes deberán elegir entre mercancías que han sido decididas por el diseñador y que conforman un abanico preexistente sobre el cual harán sus elecciones dichos compradores.

Tampoco haría algo que yo no me pondría. Yo escucho a la gente, pero por más que vengas a decirme "haceme esto" y a mí no me gusta, es difícil que te lo haga. Y creo que ninguna diseñadora te haría eso. Hay una cuestión de "bueno, hasta acá. Que te lo haga otro, disculpame. (Alejandra, diseñadora).

Así, el diseñador independiente establece relaciones comerciales con una multiplicidad de clientes. No tiene una exclusividad con determinados compradores que haga presuponer una relación laboral y tampoco se enfrenta a un mercado constituido por una demanda oligopólica que le imponga restricciones en su posibilidad de diversificar la colocación de sus productos. En todo caso, los diseñadores saben que su producción siempre apunta a un target de público, esto es, un perfil de consumidor que se identifique y adquiera sus productos -en función de su edad, género, poder adquisitivo, estilo personal, etc.--, pero dentro de este campo de referencia, los compradores potenciales son múltiples.

Esta composición variable de la demanda explica que los diseñadores dediquen parte de sus recursos a publicitar su marca y a posicionarla en distintos espacios visibles para de esta forma seguir atrayendo compradores.

Lo importante es que te conozcan. Las ferias están buenas para eso, para que vayan, se lleven un tarjetita, entren a Facebook. Eso es fundamental, estar en una red social. Te guste o no te guste, tenés que estar. (Alejandra, diseñadora).

En lo referente a los ingresos, los diseñadores se hallan en condiciones de establecer unilateralmente el valor de sus productos en función de la estructura de costos que conlleva su producción. Además, pueden adicionar a esa cifra lo que consideran ha sido el valor de su trabajo de concepción y diseño. Finalmente, pueden agregar el plus de ganancia que consideren adecuado. 
Es una conjunción de factores. Estudio mucho los precios que hay en el mercado y también, bueno, le doy valor al diseño que tiene el producto. $Y$ también de los materiales que uso. No solo los materiales, sino también el tipo de confección, de cómo está hecho. Por lo general son productos donde hay algunos que son bastante clásicos, pero hay otros que por lo general son los que tienen más costo, que son bastante complicados en el armado, en la confección. (Inés, diseñadora).

En cierta medida, estos trabajadores pueden contar con cierta posibilidad de acumulación que les permite mantener su actividad en marcha si sus niveles de venta son adecuados. Al respecto, en un estudio general del sector, Marino (2012) señala que la reinversión de ganancias y los ahorros propios son los dos primeros canales de financiamiento en orden de importancia para los diseñadores de indumentaria independientes.

En sus indagaciones, Miguel (2010) también hace referencia a los aspectos de financiamiento y señala, tras analizar las trayectorias de un número de emprendimientos de diseño independiente, que los inicios de los mismos no fueron acompañados por una gran inversión de capital dado que casi todos estos trabajadores provienen de sectores medios. Por eso, en sus discursos son reiteradas las alusiones a la idea de esfuerzo, de superación y de "hacer todo a pulmón" (Miguel, 2009:56).

Este tipo de salvedades nos impide caer en la falsa idea de que estamos ante "empresarios" de gran porte, con una extensa capacidad de acumulación. En todo caso, lo que deseamos destacar es que estos trabajadores asumen todos los riesgos económicos de su actividad y que, en principio, se hallan en condiciones de afrontarlos porque cuentan con ciertos recursos y estrategias mínimos que les permiten ir diversificando dicho riesgo y así evitar que este desempeño en la esfera del mercado constituya una situación apremiante y completamente desventajosa.

\section{Un contrapunto entre los dos casos}

En este cuarto apartado realizaremos un balance de los hallazgos surgidos del análisis de los dos grupos de trabajadores cuentapropistas que hemos seleccionado para nuestro 
estudio. Como hemos visto a partir de los datos empíricos relevados, existen marcadas diferencias entre ambos y, en este sentido, cabe ensayar algunas hipótesis explicativas.

Sin dudas, hay múltiples factores que influyen -en mayor o menor medida- en la manera en que se insertan laboralmente los colaboradores y los diseñadores de indumentaria independientes, así como en las condiciones laborales resultantes. En este sentido, podríamos mencionar distintos elementos tales como los rasgos específicos de la rama o sub sector al cual pertenecen, los contextos normativos allí vigentes, la historia de cada una de las profesiones, entre otros.

Pero consideramos que hay un aspecto esencial para comprender estas condiciones laborales diferenciales: la configuración que posee el mercado en el cual se insertan. Particularmente, en lo referido a:

- La competitividad que pueden alcanzar en dicho mercado.

- Las características de la demanda a la que se orientan.

- El grado de simetría de los intercambios resultantes.

Estos aspectos nos indican las condiciones y oportunidades -más o menos favorables- que tiene cada grupo de trabajadores en términos laborales. Para el caso de los periodistas colaboradores, la configuración del mercado en el cual venden su trabajo les impone la realización de un importante esfuerzo por alcanzar cierta continuidad laboral y, por ende, de ingresos. Estos trabajadores se enfrentan con una demanda limitada y concentrada, ya que el número de revistas y diarios en Buenos Aires representa ciertamente un número acotado. De esta manera, aun cuando son trabajadores con altas calificaciones, esto no les asegura una mayor competitividad dentro de un mercado con demanda restringida como el que enfrentan.

En este marco, la posibilidad de negociación de los colaboradores en lo concerniente a las retribuciones por su trabajo es muy baja. Estos trabajadores son tomadores de precio frente a las grandes empresas editoras -con capacidad para imponer sus condiciones- y constituyen el objeto de toda una serie de arbitrariedades como el pago diferido y a contrapublicación. En segundo lugar, el carácter oligopólico del mercado en el cual deben vender su trabajo lleva a que, para asegurarse un flujo regular de trabajo, los periodistas colaboradores intenten establecer intercambios repetidos con las empresas editoras. Así, se abre la puerta a que surjan prestaciones extendidas en el tiempo. En estos casos, se desvirtúa la figura del 
colaborador y se trata antes bien de una situación de precariedad que estos trabajadores se ven forzados a aceptar en ausencia de otras oportunidades laborales, en un escenario donde las redacciones -de plantilla estable- son numéricamente menos y más acotadas en tamaño.

Por su parte, los diseñadores de indumentaria independientes entran en vinculación con un mercado más amplio que los colaboradores y donde sus potenciales clientes son ciertamente numerosos. En todo caso, lo que se haya circunscrito es el nicho de mercado al cual apunta (target) su producción. Como hemos mencionado, se trata de consumidores interesados en adquirir productos de indumentaria altamente diferenciados, con importantes cuotas de creatividad y dispuestos a pagar un precio superior por ello.

Esto último también nos habla de las condiciones de competitividad que pueden alcanzar estos trabajadores en el vastísimo mercado de la indumentaria. Así, están en capacitados -en términos objetivos pero también legitimados en términos simbólicos- para generar una gama de productos innovadores y diferenciados respecto de la producción masiva que realizan las grandes empresas del sector. Los rasgos estéticos de sus mercancías les proveen de una ventaja competitiva no directamente atada a los precios o a las economías de escala. Asimismo, al ubicarse en este nicho específico de mercado, pueden establecer vinculaciones bastante simétricas respecto de sus compradores, aun siendo pequeños emprendedores.

\section{Conclusiones}

El contrapunto que hemos realizado más arriba permitió visualizar las diferencias más destacadas entre dos grupos de cuentapropistas en términos de sus condiciones laborales y de qué manera la configuración del mercado al cual se enfrentan permite comprender las mismas. Esta comparación nos habla, ulteriormente, de la heterogeneidad del trabajo independiente cuentapropista.

Como indicábamos al inicio de este artículo, es fundamental que este campo de discusión sea enriquecido a partir de estudios que brinden información más específica sobre este grupo ocupacional, sobre sus distintas manifestaciones y que ayuden a establecer matices, subgrupos y perfiles distintivos.

La investigación que aquí hemos presentado realiza una contribución en esta dirección, ya que hemos tomado como objeto de estudio a dos grupos cuentapropistas con un perfil 
bastante específico y que comparten un nivel de calificación similar -bastante alto- y cierta semejanza en el tipo de tareas que realizan -intelectuales y creativas-.

Pero aun siendo una franja bastante puntual dentro del trabajo cuentapropista, para la cual podría imaginarse que sus miembros tienen condiciones laborales similares -ventajosas debido a su nivel de calificación-, los resultados muestran que a su interior se ocultan una serie de especificidades que los grandes agrupamientos conceptuales y estadísticos no pueden aprehender adecuadamente.

En este sentido, un abordaje cualitativo y cercano al terreno como el que hemos emprendido nos ha dejado vislumbrar la existencia de dos situaciones laborales dentro de los independientes profesionalizados bastante disímiles: una más virtuosa y otra más cercana a la precariedad. En este punto, hemos sugerido para explicar esta divergencia la configuración que posee el mercado en el cual se insertan estos trabajadores cuentapropistas.

Queda una próspera senda para recorrer en este campo temático $\mathrm{y}$, en este sentido, alentamos la aparición de futuras investigaciones que ayuden a especificar la composición del cuentapropismo y qué rol ocupa en el modo de acumulación vigente.

\section{Bibliografía}

Arese, C. (2004). El estatuto del periodismo profesional: desde el dictáfono a Internet. Revista de Derecho Laboral, II Doctrina-Jurisprudencia-Actualidad. Buenos Aires: RubinzalCulzoni Editores.

Aubert, C. (21-22 de junio, 2007). Modes et usages des formes d'emploi dans les organes de presse écrite: vers une précarisation croissante des journalistes rémunérés à la pige? Ponencia presentada en las XIe Journées Internationales de Sociologie du Travail (JST), Londres.

Bertranou, F. y Maurizio, R. (2011). Trabajadores independientes, mercado laboral e informalidad en Argentina. Buenos Aires: OIT.

Bögenhold, D. (2003). La doble cara de la capacidad empresarial: una alternativa a la noción popular. Revista de Economía Institucional, (5) 8, pp. 161-187.

Bologna, S. (2006). Crisis de la clase media y posfordismo. Madrid: Akal. 
Correa, M. E. (2009). La producción cultural como estrategia de inserción: el caso de los diseñadores independientes de la Ciudad de Buenos Aires. Margen: revista de trabajo social y ciencias sociales, 55, pp. 1-10.

Correa, M. E. (2010). El fenómeno del Diseño independiente en la Ciudad de Buenos Aires: Análisis de la conformación de un nuevo trabajador cultural en la escena local. Tesis de Maestría en Sociología de la Cultura y Análisis Cultural, Directora: Ana Wortman, IDAESUNSAM.

D'Amours, M. y Crespo, S. (2004). Les dimensions de I'hétérogénéité de la catégorie de travailleur indépendant sans employé Éléments pour une typologie. Relations industrielles/Industrial Relations (59) 3, pp. 459-489.

Donaire, R. (2007). ¿Quiénes son los trabajadores por cuenta propia? (Argentina, 1980/2001). Lavboratorio, Año 8, 20.

Gallart, M. A.; Moreno, M. y Cerrutti, M. (1990). Estrategias laborales de los trabajadores por cuenta propia del Área Metropolitana de Buenos Aires. En Galín P. y Novick, M. La precarización del empleo en la Argentina. Buenos Aires: CEAL/CIAT/CLACSO.

Goldin, A. (2001). Las fronteras de la dependencia. Relaciones laborales: Revista crítica de teoría y práctica, 2, pp. 311-332.

Guerschman, B. (2010). La marca comercial y el diseño: una reflexión antropológica sobre la producción, el consumo y el espacio. KULA. Antropólogos del Atlántico Sur, 3, pp. 67-81.

Guerschman, B. y Vargas, P. (2007). Quilombo y apuesta. Apuntes etnográficos sobre la crisis argentina de 2001 a través de la mirada del mundo del diseño. Avá, 11, pp. 39-61.

Henry, L. (2010). Contingencias e inseguridades en los empleos flexibles. La situación de trabajo de los periodistas colaboradores de la prensa escrita. En Del Bono, A. y Quaranta, G. (comp.) Convivir con la incertidumbre: aproximaciones a la flexibilización y precarización del trabajo en Argentina. Buenos Aires: Ediciones CICCUS.

Henry, L. (2013). Flexibilización productiva y difusión del trabajo independiente en la prensa escrita argentina. Un estudio sobre las condiciones de empleo de los periodistas colaboradores. Trabajo y Sociedad, 21, pp. 1-18.

Jiménez, M. (2011). Caracterización del trabajo independiente en Argentina. Un análisis descriptivo de largo plazo, 1974-2009. En Bertranou, F. y Maurizio, R. (eds.) 
Trabajadores independientes, mercado laboral e informalidad en Argentina. Buenos Aires: OIT.

Kosacoff, B. (2004). Evaluación de un escenario posible y deseable de reestructuración y fortalecimiento del Complejo Textil argentino. Buenos Aires: CEPAL.

Lepore, E. y Schelser, D. (2006). La heterogeneidad del cuentapropismo en la Argentina actual. Una propuesta de análisis y clasificación. Trabajo, Ocupación y Empleo, 4, Subsecretaría de Programación Técnica y Estudios Laborales, MTEySS, pp. 193-226.

Marino, P. (2011). Diseño de Indumentaria de Autor en Argentina: diagnostico productivo e impacto económico basado en la Encuesta Nacional de Diseño de Indumentaria de Autor, 2011. Buenos Aires: Instituto Nacional de Tecnología Industrial (INTI).

Marino, P. (2012). Diseño de Indumentaria de Autor en Argentina: diagnostico productivo e impacto económico basado en la Encuesta Nacional de Diseño de Indumentaria de Autor, 2012. Buenos Aires: Instituto Nacional de Tecnología Industrial (INTI).

Mastrini, G. y Becerra, M. (2006). Periodistas y magnates: estructura y concentración de las industrias culturales en América Latina. Buenos Aires: Prometeo.

Maxwell, J. A. (1996). Qualitative research design. An interactive approach. Londres: Sage Publications.

Miguel, P. (2009). Los recorridos del diseño de indumentaria en la ciudad de Buenos Aires. Apuntes de Investigación del CECYP, 15, pp. 51-73.

Miguel, P. (2010). Creatividad y éxito en un contexto adverso: la paradójica conformación del campo de producción de diseño de indumentaria en la Ciudad de Buenos Aires (20002005). Tesis de Doctorado en Ciencias Sociales, Facultad de Ciencias Sociales. Dirección: Carolina Mera, Universidad de Buenos Aires (mimeo).

Mon, L. (2012). Industrias Creativas de Diseño de Indumentaria de Autor. Diagnóstico y desafíos a 10 años del surgimiento del fenómeno en Argentina. Cuaderno 42, Centro de Estudios en Diseño y Comunicación, año 13, 42, pp. 19-34.

Neffa, J. C. (2010). La crisis de la relación salarial: naturaleza y significado de la informalidad, los trabajos/empleos precarios y los no registrados. Documento de Trabajo de la serie Empleo, desempleo y políticas de empleo, 1. Buenos Aires: Ceil del Conicet.

Pérez Zelaschi, M. (2012). Observatorio de tendencias. Cuaderno 42, Centro de Estudios en Diseño y Comunicación, año 13, 42, pp. 35-42. 
De Prácticas y discursos/ Universidad Nacional del Nordeste/ Centro de Estudios Sociales

Poblete, L. (2008). De la Gestion de I'Autonomie. Parcours de Travailleurs Autonomes Argentins dans les Années 90, Tesis Doctoral, École des Hautes Études en Sciences Sociales (EHESS), Paris.

Postolski, G.; Santucho, A. y Rodríguez, D. (2007). Concentración de los medios de comunicación en Argentina: crisis y dependencia. Portal IADE/Realidad Económica. Disponible en: <http://www.iade.org.ar/modules/noticias/article.php?storyid=1926> [consultado el 14 de julio de 2016].

Smeaton, D. (2003). Self-employed workers: calling the shots or hesitant independents? A consideration of the trends. Work, employment and society, (17) 2, pp. 379- 391.

Stanworth, C. y Stanworth, J. (1995). The self-employed without employees-autonomous or atypical? Industrial Relations Journal, (26) 3, pp. 221-229.

Supiot, A. (2000). Les noveaux visages de la subordination. Droit Social, 2, pp. 131-145.

Tremblay, D. G. y Genin, E. (2010). IT Self- employed workers between constraint and flexibility. New Technology, Work and Employment, (25) 1, pp. 34-48.

UNCTAD (2010). Economía creativa. Informe 2010. Economía Creativa: una opción factible de desarrollo. Ginebra: Naciones Unidas.

Vargas, P. (2007). Pequeños empresarios del mundo del diseño ¿originalidad o innovación? Una primera aproximación etnográfica a los casos argentino y mexicano. Revista Electrónica Ide@s CONCYTEG, año 2, 27.

Verd Pericás, J. M. y Martí Olivé, J. (1999). Muestreo y recogida de datos en el análisis de redes sociales. Questiió, (23) 3, pp. 507-524.

Zallo, R. (1988). Economía de la comunicación y la cultura. Madrid: Akal. 